\title{
A reforma do Poder Judiciárío sob a ótica do governo federal
}

Sérgio Rabello Tamm Renault

A reforma do Judiciário é daqueles temas que, volta e meia, retornam à agenda política do País, suscitando discussões infindáveis e inconclusas. É necessário reconhecer, contudo, que, nos últimos anos, o assunto passou a ser realmente enfrentado como uma questão de Estado e que avanços importantes foram alcançados. A morosidade da Justiça, a obsolescência, a ineficiência e a pouca transparência da máquina pública a serviço do Poder Judiciário são alguns dos problemas apontados aqui e ali a justificar a necessidade da reforma. $\mathrm{Na}$ assembléia constituinte que elaborou a Constituição Federal, em vigor desde 1988, e nas diversas oportunidades surgidas no âmbito do Congresso Nacional a partir de então, temas relacionados ao aperfeiçoamento do Poder Judiciário foram freqüentemente recolocados. A verdade é que há um certo consenso, entre os que se ocupam a refletir sobre o tema, de que o Poder Judiciário precisa passar por uma reforma. Mas que reforma é essa de que tanto se fala? 
A primeira questão que se coloca é a necessidade de definir os objetivos fundamentais a serem alcançados com a reforma. O primeiro deles deve ser o da ampliação do acesso das pessoas à prestação jurisdicional do Estado, a partir do reconhecimento de que não há exercício pleno de cidadania sem a possibilidade de acesso a esse serviço essencial. Em um país marcado por vergonhosas desigualdades sociais como o Brasil, o problema do acesso assume proporções realmente preocupantes. O outro objetivo da reforma deve ser o de garantir que os serviços prestados àqueles que a eles têm acesso sejam de melhor qualidade. Em outras palavras, não basta o acesso, é necessária também a qualidade do serviço.

Convém destacar a necessidade de haver um diagnóstico sobre os principais problemas que explicam o mau funcionamento do sistema judicial no Brasil. De forma bastante sintética, podemos afirmar que esses principais problemas são os seguintes:

- Lentidão na tramitação dos processos judiciais - Não há dúvidas de que a tramitação dos processos no Brasil é muito lenta e que esse é o problema apontado normalmente pela população como o grande mal do nosso sistema judicial.

- Pouca transparência-O sistema judicial brasileiro é hermético, refratário a mudanças e de difícil compreensão por parte dos operadores do Direito e da população em geral. O que verificamos no decorrer dos anos é que o Judiciário nunca se abriu publicamente para que seus problemas e suas dificuldades fossem partilhados por todos agentes e não se verificou uma preocupação nacional em relação à necessidade de formulação de uma política pública para o seu melhor funcionamento.
- Obsolescência administrativa-O Judiciário brasileiro precisa chegar ao século XXI. De todas as instituições do Estado, a que menos se modernizou, nos últimos anos, no País, foi o Poder Judiciário, seja por falta de recursos, seja por falta de compreensão do papel fundamental que exerce em favor da cidadania. A utilização adequada dos recursos tecnológicos disponíveis no mercado é uma urgência inegável para que o Judiciário possa, efetivamente, prestar os serviços demandados pela população.

- Dificuldade de acesso - Como já mencionado, parte significativa da população brasileira não tem sequer acesso aos serviços jurisdicionais prestados pelo Estado, o que por si só demonstra que a reforma do Judiciário, entendida, no seu sentido mais amplo, é providência necessária para o aperfeiçoamento da nossa democracia.

- Complexidade estrutural - O sistema judicial brasileiro é composto por uma série de órgãos e estruturas que dificultam sua compreensão. Essa complexidade estrutural decorre da forma como a Constituição Federal determina a própria or ganização do Poder Judiciário e também da evolução da organização da instituição no decorrer da história, considerando-se os diferentes níveis de demanda social pelos serviços jurisdicionais prestados pelo Estado. Não há, no Brasil, um só Poder Judiciário. Há, na verdade, vários poderes judiciários. Temos a Justiça Federal, a Justiça comum dos estados da Federação, as Justiças especializadas (militar, trabalhista e eleitoral), a primeira e a segunda instâncias, os tribunais superiores, os juizados especiais, etc. Em suma, temos 91 tribunais com grande nível de autonomia administrativa e praticamente nenhuma interligação entre eles ou, conforme se expressou o ministro Sepúlveda 
Pertence, do STF, esses tribunais são "ilhas de um grande arquipélago sem nenhuma comunicação entre elas".

- Concentração de litigiosidade - Há no Brasil grande quantidade de processos em tramitação - algo em torno de um processo para cada sete habitantes, conforme comprovam os dados do Diagnóstico do Poder Judiciário $^{1}$, realizado pela Secretaria de Reforma do Judiciário do Ministério da Justiça em 2004. Esse expressivo número pode, à primeira vista, dar a impressão de que a população brasileira exerce efetivamente o seu direito de recorrer à Justiça, mas não é bem assim. O que verificamos é uma excessiva concentração de processos de interesse das grandes corporações empresariais e dos governos federal, estadual e municipal. Essa concentração de litigiosidade tem implicações inegáveis no mau funcionamento do Judiciário, na medida em que é responsável, em parte, pelo congestionamento dos tribunais.

- Desarticulação institucional-A identificação da reforma do Poder Judiciário como tema prioritário para o País não representa propriamente nada de novo. Como se sabe, há muito que se fala sobre esse tema. O que há de novo é o fato de o assunto passar a ser considerado uma questão de Estado, com as implicações daí decorrentes. Durante muitos anos, não havia o envolvimento dos agentes públicos e dos outros poderes com as questões relativas ao sistema judicial. O Judiciário era assunto de interesse dos magistrados e de suas entidades de classe. Hoje já verificamos o início de uma articulação institucional que busca solução para os problemas do Judiciário, com o entendimento de que isso é fundamental para o País. A avaliação que se faz é a de que a formulação de uma política pública para o Poder Judiciário é, sim, assunto que interessa a todo o País. Interessa, por exemplo, ao Poder Ex ecutivo, ou melhor, a um governo que, eleito democraticamente pela população, pr etenda dedicar-se às questões nacionais mais relevantes para o aperfeiçoamento da democracia em nosso país.

A descrição das questões anteriormente mencionadas revela, de forma bastante clara, a extensão e a diversidade dos problemas existentes. Por essa razão, a reforma do Judiciário deve ser entendida

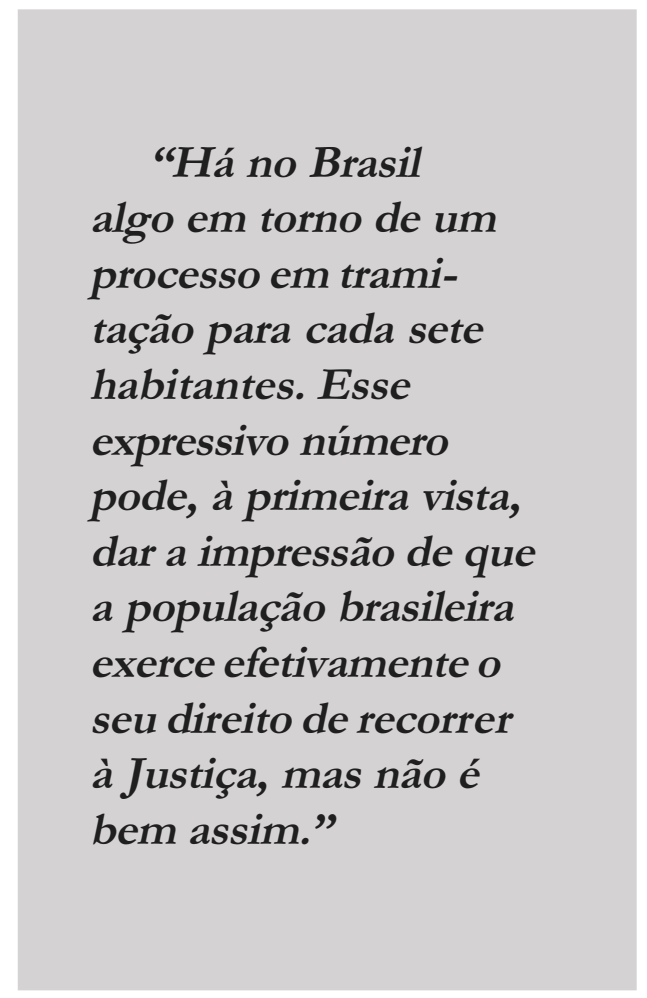

como um processo que implique a tomada de uma série de medidas que, conjuntamente, poderão repercutir positivamente na solução desses problemas. Não há soluções mágicas, capazes de resolvê-los todos de repente. Aspecto positivo, que há de ser reconhecido, é o momento político-institucional altamente favorável que estamos vivendo a partir da aprovação da reforma constitucional. 
Com efeito, hoje, a preocupação com os assuntos referentes ao sistema judicial está disseminada e presente em todos os momentos em que se discutem os assunto mais relevantes para o País. Assim é que, em dezembro de 2004, uma semana após a promulgação da reforma constitucional do Poder Judiciário, foi assinado, pelos presidentes da República, do Senado Federal, da Câmara dos Deputados e do Supremo Tribunal Federal, o "Pacto em favor de um Judiciário mais rápido e republicano", documento pelo qual os chefes dos três poderes comprometeramse publicamente pela realização de seus melhores esforços para implementar uma série de medidas que visam, em última análise, a provocar a melhoria do funcionamento de nosso sistema judicial e revelar o verdadeiro sentido da reforma do Judiciário.

Essas medidas compreendem o desenvolvimento de, basicamente, três conjuntos de ações coordenadas entre si, que são: diagnóstico, modernização do Judiciário e alterações legisla tivas.

A realização de um diagnóstico profundo e global do Poder Judiciário é necessária para que se conheça melhor a estrutura dessa instituição. A verdade é que o operador do Direito, seja juiz, membro do Ministério Público, defensor público, advogado ou serventuário da Justiça, não conhece gobalmente o funcionamento do Judiciário. Cada um provavelmente conhece a realidade do universo com o qual se relaciona profissionalmente, mas esse conhecimento é sempre parcial e não permite que se traduza em diagnóstico global.

Em 2004, a Secretaria de Reforma do Judiciário do Ministério da Justiça realizou, com consultoria da Fundação Getúlio Vargas, de São Paulo, o primeiro Diagnóstico do Poder Judiciário, tendo realizado pesquisas junto aos todos os tribunais do País e consultas ao Banco Nacional de Dados do Poder Judiciário, mantido pelo Supremo Tribunal Federal. Apesar de utilizar somente informações oficiais, o trabalho sofreu críticas, principalmente das entidades associativas da magistratura, mas cumpriu inegavelmente o papel de iniciar publicamente a discussão sobre a necessidade de que o Judiciário seja mais conhecido e transparente aos olhos da sociedade. A partir desse diagnóstico, outros trabalhos com o mesmo objetivo foram anunciados, como a análise realizada pelo Supremo Tribunal Federal e a presentada em maio de 2005. O conhecimento sobre o funcionamento do Judiciário deverá possibilitar a identificação das suas dificuldades e as experiências bemsucedidas de gestão em funcionamento.

Além do conhecimento sobre o funcionamento do Judiciário, suas mazelas e aspectos positivos, o diagnóstico deverá ainda fornecer elementos que per mitam a definição de indicadores de eficiência, produtividade e qualidade para o Poder Judiciário.

A segunda ação em desenvolvimento prevê a implementação de medidas de modernização do Poder Judiciário. Tratase de ações que independem de alterações ou proposições legislativas. Parte-se da premissa de que a reforma do Judiciário passa pela modernização da sua gestão. A incorporação de novas tecnologias de informação, a padronização de procedimentos racionais, a simplificação de sistemas operacionais, a capacitação de pessoal, o apoio a projetos de financiamento para a modernização e a desburocratização da máquina administrativa são exemplos de iniciativas que podem tornar o Judiciário mais eficiente e ágil. A melhor metodologia a ser desenvolvida é a da captação das 
melhores experiências de gestão (bestpractices), com o fim de valorizá-las, torná-las públicas e provocar a sua implementação em outras localidades e em outros juizados.

A identificação das melhores práticas de gestão do Judiciário deverá ser feita a partir de uma metodologia concebida para que se valorize efetivamente o trabalho já desenvolvido pelo próprio Judiciário, demonstrando que a reforma será feita com os juízes e por eles mesmos.

As iniciativas de modernização de gestão mais desenvolvidas em funcionamento são os juizados especiais federais em algumas regiões do País. Essas experiências representam avanço significativo de implementação de novas tecnologias e já permitem a informatização total de processos judiciais (processos virtuais), sem a tramitação de papéis. Deve-se observar que a implementação desses processos informatizados foi possível em virtude das peculiaridades de que se revestem esses juizados especiais federais, onde, no bolo passivo das ações judiciais, está quase sempre o Estado (União ou INSS) e os tipos de ações são em número limitado. A demanda desses juizados tem crescido enormemente nos últimos meses em todo o País, o que ocorre em virtude da boa qualidade do serviço prestado, principalmente em comparação com aquele que se presta na Justiça comum. A implementação dessa ação partirá inicialmente da adaptação dessas experiências para a Justiça estadual e para os juizados de execução fiscal.

Nesse contexto, encontram-se ainda as medidas destinadas a melhor capacitar os servidores do Judiciário, principalmente os magistrados, para o exercício das atividades administrativas pelas quais são responsáveis e para as quais não recebem, na maior parte das vezes, nenhum treinamento. Objetiva-se aqui viabilizar a realização de cursos preparados especialmente para capacitação de juízes na área de gestão administrativa do Poder Judiciário. Tem-se como certo que se fez no Brasil a opção para que as atividades administrativas do Judiciário fossem exercidas pelos próprios juízes e não por administradores profissionais, como ocor re em alguns países.

Vale, finalmente, mencionar a preocupação com a postura do Estado (União,

"As iniciativas de modernização de gestão mais desenvolvidas em funcionamento são os juizados especiais federais em algumas regiões. Elas representam avanço significativo de implementação de novas tecnologias e já permitem a informatização total de processos judiciais, sem a tramitação de papéis"

estados e municípios) em relação ao Judiciário. Como se diz, comumente, o governo é o maior cliente do Poder Judiciário - algo em torno de $80 \%$ dos processos e recursos que tramitam nos tribunais superiores tratam de interesses do governo, seja ele federal, estadual ou municipal. Nesse sentido, estamos convencidos de que se deve buscar a definição de uma nova conduta do Estado em relação ao 
Judiciário. Partindo dessa premissa é que foi criado, por portaria interministerial, um grupo de trabalho ${ }^{3}$ no âmbito do governo federal, com o objetivo de definir a nova conduta dos diversos órgãos do governo federal, por meio da tomada de medidas que inibam a propositura de ações judiciais ou interposição de recursos sobre matérias a respeito das quais já exista jurisprudência razoavelmente pacificada. A competência da Advocacia-Geral da União para a expedição de súmulas administrativas deve ser exercida de modo que haja resultados efetivos do ponto de vista da diminuição relativa do número de processos de interesse do governo.

A terceira ação firmada no Pacto referese às medidas que implicam alteração legislativa, compreendendo as infraconstitucionais e as constitucionais. Avalia-se que as alterações da legislação infraconstitucional podem trazer maior celeridade aos processos judiciais.

O Pacto é integrado por 23 projetos de lei, elaborados e identificados na Secretaria de Reforma do Judiciário e já enviados ao Congresso Nacional. Eles alteram a legislação processual civil, trabalhista e penal, com o propósito de, garantido o princípio constitucional do amplo direito de defesa, assegurar a tramitação mais célere dos processos judiciais.

A título exemplificativo, pode ser citado o projeto que prevê a instituição de procedimentos de solução alternativa de conflitos, como a medição e a conciliação; o projeto que simplifica o processo de execução de títulos judiciais (PL no 52/ 04, no Senado) e de títulos extrajudiciais (PL no 4497/04, que acaba de ser aprovado pela Câmara); os projetos que dispõem sobre regras inibidoras de recursos protelatórios (PL n ${ }^{\circ} 4724 / 04$ e PL n ${ }^{\circ}$ 4727/04, ambos na Câmara), sobre a diminuição do número de recursos previstos no código de processo civil e sobre o fortalecimento dos juizados especiais (PL no 4723/04, em tramitação na Câmara).

Por fim, deve-se ressaltar a necessidade de serem regulamentados e concretizados os avanços contidos na Reforma Constitucional do Judiciário (Emenda $\mathrm{n}^{\circ} 45$ ).

A reforma constitucional do Judiciário foi aprovada no final de 2004, após 12 anos de tramitação no Congresso Nacional. A alteração dos dispositivos constitucionais sobre a Justiça brasileira era objeto de discussão no Poder Legislativo desde 1992. Os debates que permearam a tramitação legislativa da proposta envolveram juízes, promotores, defensores públicos, advogados, acadêmicos e a sociedade civil, no sentido de construir um modelo institucional de justiça adequado às expectativas sociais atuais. Idéias e sugestões foram aportadas e debatidas com profundidade e seriedade, para que o texto final apresentasse um sistema judicial funcional, acessível e racional.

A Emenda Constitucional no 45 é o resultado final desse rico processo de reflexão e constitui um documento histórico, que demonstra a maturidade de um Poder Legislativo que soube erigir um novo regramento para o Judiciário nacional.

As principais inovações que a $\mathrm{EC} \mathrm{n}^{\circ}$ 45 traz consigo são:

- Planejamento e controle do Poder Judiciário A criação de órgãos de controle externo do Poder Judiciário e do Ministério Público (Conselho Nacional de Justiça e Conselho Nacional do Ministério Público), por meio da inserção dos arts. 103-B e 130-A na Constituição Federal, foi apontada pelo governo como uma das condições fundamentais para que o Poder Judiciário tor nese mais transparente e esteja submetido a algum nível de controle da sociedade. 
O Conselho Nacional de Justiça, composto por 15 membros ( 9 magistrados, 2 membros do Ministério Público, 2 advogados e 2 cidadãos), terá, por atribuição principal, a atividade de planejar a implementação de políticas judiciais em todo o território nacional. Sua importância reside na possibilidade de integrar programas de informatização, de qualificação de servidores, de acesso à Justiça e de gestão administrativa, em toda a Justiça estadual e federal, atividade antes impossível devido ao isolamento político dos tribunais. A unificação de procedimentos e a competência de pensar o sistema de justiça como estrutura nacional e integrada são o desafio e a razão de ser desse órgão.

- Eficiência e celeridade do Judiciário Como já se afirmou, não se considera que as alterações constitucionais trarão, isoladamente, maior celeridade para a tramitação processual, mas algumas novidades apontam para maior racionalidade de todo o sistema. A instituição da polêmica súmula vinculante e da repercussão geral como requisito necessário do recurso extraordinário decorre do reconhecimento, agora expresso no rol de direitos fundamentais do cidadão, do direito a um processo judicial e administrativo célere. A utilização responsável desses instrumentos poderá ser importante para inibir a litigância protelatória, especialmente aquela realizada pelo poder público, que responde por grande volume de processos na Justiça.

- Autonomia e independência dos magistrados - É aspecto fundamental da reforma a afirmação dos princípios constitucionais da autonomia e independência dos magistrados. As principais inovações relativas a esse princípio são as que tratam da autonomia financeira do Poder Judiciário, do estabelecimento de critérios unificados para ingresso na magistratura e no Ministério
Público e da instituição da quarentena para o exercício da advocacia por parte dos juízes depois de exercerem essa atividade.

- Funções essenciais e acesso à Justiça - O fortalecimento das funções da Justiça definidas na Constituição Federal como essenciais é condição necessária para o fortalecimento do próprio Poder Judiciário. Nesse sentido, a concessão de autonomia às defensorias públicas foi um passo fundamental para a solidificação de polí-

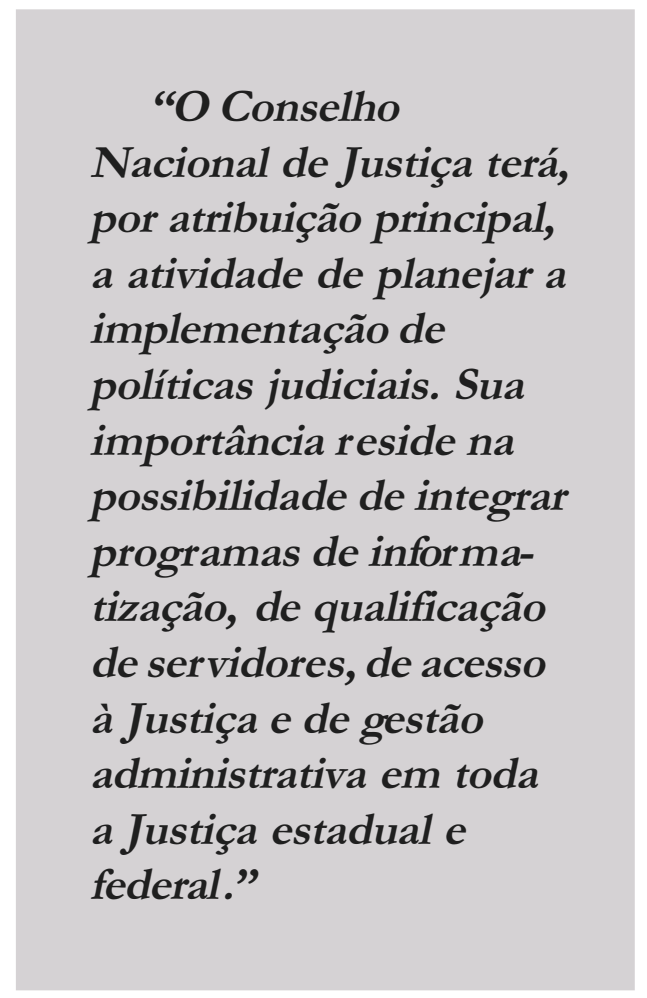

ticas responsáveis de acesso à Justiça no País. Diagnóstico realizado pela Secretaria de Reforma do Judiciário demonstrou que a estrutura das defensorias públicas deixa muito a desejar, e a conquista da autonomia permitirá a essas instituições o desenvolvimento adequado para exercer seu papel imprescindível de representação e orientação judicial aos setores sociais menos abastados. 
Esses novos dispositivos constitucionais são um marco institucional imprescindível. Sua regulamentação e implementação apresentam-se como o novo desafio à reforma do Judiciário. A instalação dos órgãos de planejamento, a utilização material das novas regras de processo, o fortalecimento efetivo das carreiras judiciais serão os próximos passos que aproximarão a Justiça dos objetivos já delineados.

A ampliação do acesso da população ao Judiciário e a melhoria de sua gestão somente ocorrerá a partir do desenvol- vimento coordenado de todas as ações mencionadas. Nesse sentido, a concretização da reforma constitucional, a a provação das leis processuais e a modernização da gestão judicial são vertentes indispensáveis para conferir ao sistema judicial brasileiro um caráter democrático, transparente e eficiente, fundamental para a própria consolidação do Estado democrático de direito.

(Artigo recebido em maio de 2005. Versão definitiva em junho de 2005)

\section{Notas}

${ }^{1}$ Disponível em: <http://www.mj.gov.br/reforma $>$.

${ }^{2}$ A íntegra do pacto está disponível em: <http://www.mj.gov.br/reforma $>$.

${ }^{3}$ Portaria Interministerial no 1.131 , de 14 de agosto de 2003, publicada no DOU de 15/8/2003. 


\section{Resumo - Resumen - Abstract}

\section{A reforma do Poder Judiciário sob a ótica do governo federal Sérgio Rabello Tamm Renault}

Este artigo discute os principais aspectos do processo de reforma do Poder Judiciário, tendo como ponto de partida os objetivos a que ela se propõe: a ampliação do acesso à Justiça e a melhoria da qualidade dos serviços prestados. Inicia-se destacando os problemas do sistema judicial brasileiro. Ressalta, a partir daí, o conjunto de medidas constante no "Pacto em favor de um Judiciário mais rápido e republicano", firmados pelos representantes máximos dos três poderes. A primeira delas constitui a realização de um diagnóstico do Judiciário. A se gunda ação diz respeito à modernização de sua gestão, por meio, entre outros, da ca pacitação de servidores no exercício das atividades administrativas e da incorporação de novas tecnologias. Por fim, integram-se a esse conjunto iniciativas de alteração legislativa.

Palavras-chave: Poder Judiciário, refor ma, diagnóstico

\section{La reforma del Poder Judiciario desde la perspectiva del gobierno feder al Sérgio Rabello Tamm Renault}

Este artículo discute los aspectos principales del proceso de reforma del Poder Judiciario, teniendo como punto de partida los objetivos que busca lograr: la ampliación del acceso a la justicia y la mejoría de la cualidad de los servicios judiciales. Empieza destacando los problemas del sistema judicial brasileño. Señala, a partir de eso, un conjunto de medidas que constan en el "Pacto a favor de un Judiciario más rápido y republicano”, firmados por los representantes máximos de los tres poderes. La primera medida constituye la realización de un diagnostico del Judiciario. La segunda acción se refiere a la modernización de la gestión del Judiciario a través, entre otros, de la capacitación de sus servidores en el ejercicio de las actividades administrativas y de la incorporación de nuevas tecnologías. Finalmente, se integran a ese conjunto iniciativas de alteración legislativa.

Palabras clave: Poder Judiciario, reforma, diagnóstico

\section{The reform of the Judiciary from the federal gover nment perspective Sérgio Rabello Tamm Renault}

This article discusses the main aspects of the Brazilian judicial reform process, considering as a starting point its major objectives: broadening access to justice and improving the quality of the judicial services. It be gins by providing a brief overview of the problems of the Brazilian judicial system. It then highlights the set of measures agreed among the highest representatives of the three branches, the "Pact in favor of a more expeditious and republican Judiciary". The first course of action constitutes the diagnosis of the situation. The second refers to the modernization of the Judiciary management through, namely, the enhancing of capacities and skills of its managers and servants, as well the incorporation of new technologies. Finally, the set of measures includes initiatives of legislative alteration.

Key words: The Judiciary, refor m, diagnosis

Sérgio Rabello Tamm Renault

Secretário de Reforma do Judiciário do Ministério da Justiça, é formado em Direito pela Universidade de São Paulo e especialista em Direito Administrativo pela mesma universidade. Contato: sergio.renault@mj.gov.br. 


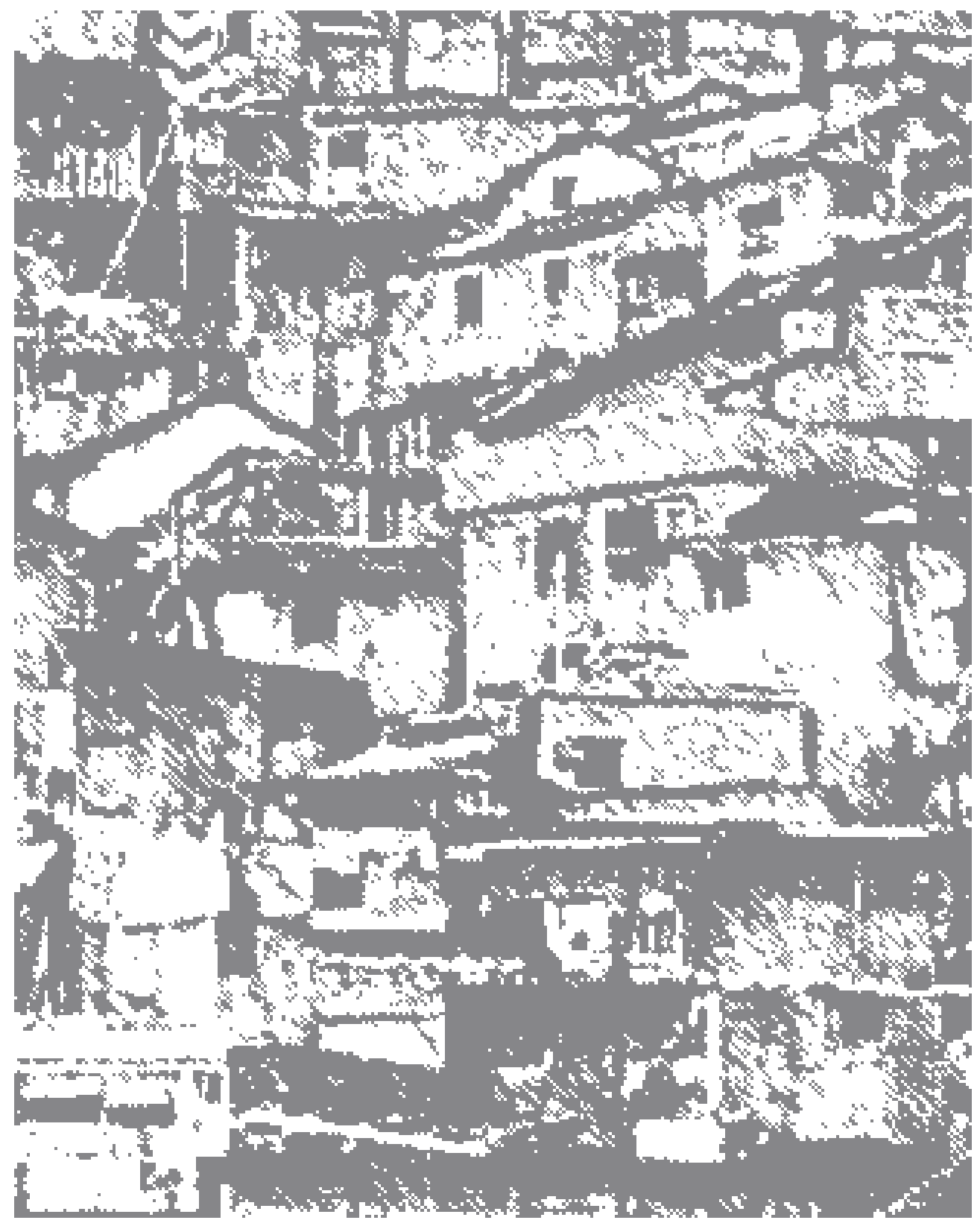

